This is a self-archived - parallel published version of this article in the publication archive of the University of Vaasa. It might differ from the original.

\title{
A High Step-Up Transformerless DC-DC Converter with New Voltage Multiplier Cell Topology and Coupled Inductor
}

Author(s): Sarvghadi, Pouria; Varjani, Ali Yazdian; Shahparasti, Mahdi

Title:

A High Step-Up Transformerless DC-DC Converter with New Voltage Multiplier Cell Topology and Coupled Inductor

Year: $\quad 2021$

Version: Accepted article

Copyright C2021 IEEE. Personal use of this material is permitted. Permission from IEEE must be obtained for all other uses, in any current or future media, including reprinting/republishing this material for advertising or promotional purposes, creating new collective works, for resale or redistribution to servers or lists, or reuse of any copyrighted component of this work in other works.

Please cite the original version:

Sarvghadi, P., Varjani, A. Y. \& Shahparasti, M. (2021). A High Step-Up Transformerless DC-DC Converter with New Voltage Multiplier Cell Topology and Coupled Inductor. IEEE Transactions on Industrial Electronics. https://doi.org/10.1109/TIE.2021.3135625 


\title{
A High Step-Up Transformerless DC-DC Converter with New Voltage Multiplier Cell Topology and Coupled Inductor
}

\author{
Pouria Sarvghadi, Ali Yazdian Varjani, Member, IEEE, Mahdi Shahparasti, Member, IEEE
}

\begin{abstract}
In this paper, a new high step-up transformerless DC-DC converter based on voltage multiplier and coupled inductor topology is presented. The proposed converter has two stages. In the first stage, a modified boost converter is designed by the coupled inductor and in the second stage, a new voltage multiplier by using a coupled inductor was illustrated. In this converter, high voltage gain can be achieved by adjusting the turn ratio of two coupled inductors and duty cycle which result in three degrees of design freedom. Using a single power switch with low on-resistance in the converter structure leads to simple control and low conduction loss. Also, total voltage stresses of active elements are decreased which cause to increase efficiency. Steady-state performance and theoretical achievements are confirmed by experimental test results on a test setup with one $200 \mathrm{~W}$ DC-DC prototype.
\end{abstract}

Keywords: coupled-inductor, high step-up, transformerless, dc-dc converter, high voltage gain

\section{INTRODUCTION}

Nowadays, with increasing energy consumption and environmental concerns, renewable energy sources such as wind and photovoltaic have become attractive topics in both academia and industry [1]. Photovoltaic systems need less periodic maintenance and they have no rotating elements. In addition, having a long life along with the above advantages leads to increase installation capacity continuously [2]-[3]. But it should be noted that the low output voltage of the photovoltaic (PV) panel is a challenge in their use. Series connection of the $\mathrm{PV}$ panels is the easiest way to increase voltage levels In this way, the existence of shadow and cloud effect or failure in any panel leads to reduced reliability as well as system efficiency [4], [5]. Using a transformer along with the converter topology is a simple solution to increase the output voltage of the PV panel [6].

Manuscript received Jan 18, 2021; revised Oct 12, 2021; accepted Dec 2, 2021.

Pouria Sarvghadi and Ali Yazdian Varjani are with Department of Electrical and Computer Engineering, Tarbiat Modares University of Tehran 14115-143, Iran (e-mail: p.sarvghadi@modares.ac.ir yazdian@modares.ac.ir)

Mahdi Shahparasti is with the School of Technology and Innovations, University of Vaasa, 65200 Vaasa, Finland (email: mahdi.shahparasti@uwasa.fi)
Full bridge, push-pull, flyback and forward are familiar topologies that using a transformer in their structure [7], [8]. In these topologies, high voltage gain can be achieved by increasing the turn ratio of the transformer [9]. As a result, leakage inductance will increase by high turn ratio of the transformer that leads to reverse recovery problem and switching loss [10], [11].

In recent years, high step-up transformerless (HSUT) DC-DC topologies have been proposed to solve the above problems [4]. Hence, low switching loss, volume and cost are some advantages of the transformerless converter. Moreover, high efficiency and high power density complete the above benefits [10], [12]. HSUT DC-DC converters can be categorized as, boost, cascade boost, Z-Source, switch capacitor, coupled inductor, multilevel and voltage multiplier [13], [14]. Boost topology is a basic HSUT DC-DC converter. Although this topology has an infinite gain in theory, the high voltage stress and parasitic problem limit the gain of this converter in real application [1]. The poor efficiency and reverse recovery problem are other drawbacks of the boost converter [15]. Cascade boost converters have a high gain but control of these are complicated due to the high number of conversion stages [16]. Usually, two high gain converters are connected in a back to back way. The first stage works with a higher switching frequency and for lossless operation, the second stage works with a lower frequency [17]. The high number of required components and low reliability are some drawbacks of the cascade converter [18].

The DC/DC Z-source converters, as another family of HSUT converters, operate based on the shoot through among DC link and then charging inductor and capacitor in their circuit [19], [20]. After the shoot through, the saved energy of the passive element is accumulated by the dc-link and then voltage boosting is occur. Due to the use of many passive elements, the cost and volume are high in Z-source converters [21]. Further, high voltage stress and current spike in this topology lead to switching loss and consequently low efficiency [22].

Using switch capacitor converters is another way to attain high voltage gain. These topologies adopt an uncomplicated circuit but they need to use many capacitors for reaching high voltage gain which results in reducing the lifetime of the converter [23]. Moreover, the high number of switches in these converters leads to poor efficiency and high complexity in control [24]. Further, the dependence of voltage gain on the arrangement of capacitors is another disadvantage of switch capacitor converters [25]. 


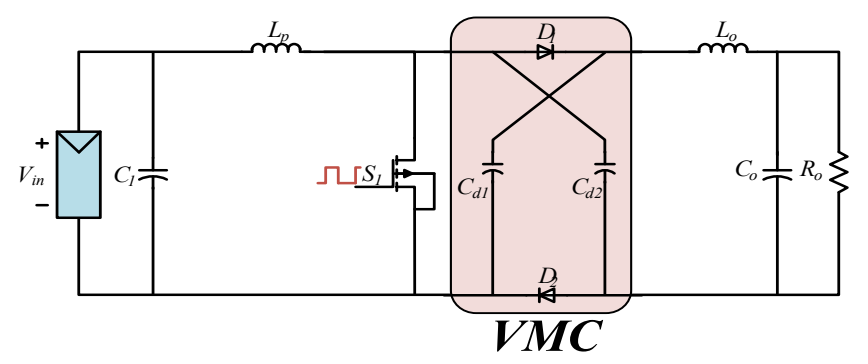

Fig. 1. Arranged VMC in conventional boost converter [14]

HSUT DC-DC converters with coupled inductors have been presented in [5], [26]. In these topologies, windings wrap around one core that leads to low weight and volume and also high power density and efficiency [27]. High gain can be achieved by increasing the number of turn ratios in the coupled inductor [25], [28].

Similarly, voltage multiplier (VM) is a simple, efficient and low cost that consists of diodes, capacitors and inductors [29]. Basic VM is shown in Fig. 1, which consists of two diodes and two capacitors.

As shown in Fig. 1, a high voltage gain can be achieved by inserting VM after the active switch in the boost topology [14]. From Fig. 1, capacitors will be charged and discharged by turning off and on the active switch respectively. VMs are suitable for high output voltage and low output current converters [29]. Despite the mentioned benefits, but the main weakness of VM is a fixed gain [29]. This means that adjusting the gain of this converter is done by changing the duty cycle of the active switch and the VM stage has a fixed gain that, multiplies in boost gain.

Considering the above description and deficiency of high stepup converters, a new HSUT DC-DC converter with voltage multiplier and coupled inductors will be proposed in this paper. High voltage gain can be achieved by a new voltage multiplier and coupled inductors structure which solved the fixed gain problem. The proposed converter includes a single switch that simplifies converter control and it is suitable for PV applications. Besides, the proposed topology gives three degrees of design freedom. This means that voltage gain can be adjusted by the duty cycle as well as the turn ratio of coupled inductance in the first stage and turn ratio of coupled inductance in the second stage. Also, the proposed topology can work in the low duty cycle. With a lower duty ratio, voltage and current stresses on the components are decreased which results to reduce conduction loss. In the next sections, operation mode and steady-state analysis of the proposed converter is investigated in section II. Then, related equations will be discussed in section III. Next, comparison study and experimental results were investigated in sections IV and V respectively. Finally, section VI concludes the paper.

\section{STEADY-STATE ANALYSIS}

The proposed topology is shown in Fig. 2 which has two high step-up stages. In the first stage, a modified boost converter is designed by the coupled inductor and in the second stage, a new voltage multiplier by using a coupled inductor is implemented.

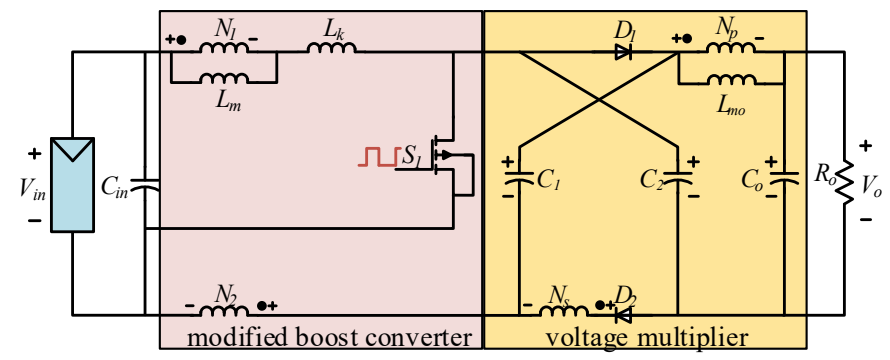

Fig. 2. Proposed converter based on voltage multiplier and coupled inductors

The proposed converter consists of one active switch $S_{l}$, two coupled inductor $L_{m} \& L_{m o}$, two diode $D_{1} \& D_{2}$ and two capacitors $C_{1} \& C_{2}$. For increasing voltage gain, a new voltage multiplier and a coupled inductor topology are combined with a modified boost topology.

This proposed topology has three operation modes as shown in Fig. 3. In order to simplify, the following assumptions are considered:

1) All semiconductor components are ideal without any loss.

2) All capacitors are large enough, so their ripple can be ignored.

3) The proposed converter operates in CCM conditions.

4) Ignore leakage inductance of the coupled inductors in the operation condition

MODE I ( $\left.\boldsymbol{t}_{0}-\boldsymbol{t}_{\boldsymbol{l}}\right)$ : In this mode, active switch $S_{l}$ is turned on by gating pulse signal, and magnetizing inductance $L_{m}$ is charged by input dc voltage source. $D_{1}$ and $D_{2}$ are in blocking mode and magnetizing current of $L_{m o}$ is increased by energy stored at VM stage capacitors $C_{I}$ and $C_{2}$. Based on Fig. 3(a), the load current is supplied by capacitor $C_{o}$. This mode is finished when the switch is turned off. The key waveform of this mode is represented in Fig. 3(a).

MODE II $\left(\boldsymbol{t}_{1}-\boldsymbol{t}_{2}\right)$ (intermediate mode): This intermediate time interval is shown in Fig. 3(b) where $S_{1}$ goes to the off state. Due to the inductor current is kept in continuous conduction mode, $D_{2}$ is working in conduction mode and its current is greater than zero. The diode $D_{l}$ is in forward bias but its current is zero. This causes an intermediate interval but has no effect on the voltage equations of the proposed topology. In this intermediate mode, $D_{l}$ is in the forward bias, but due to the discharge of the output magnetizing current in the capacitor $C_{l}$, its current is zero. Therefore, $C_{2}$ is charged by the input current. Output inductance current ILmo decreases linearly and also $C_{l}$ charges by this current. A detailed visual representation is shown in Fig. 3.

MODE III $\left(t_{2}-t_{3}\right)$ : In this time interval, $S_{l}$ is still at the off state and $D_{l}$ goes to conduction mode (see Fig. 3(c)). Primary (VN1, $\mathrm{VNp})$ and secondary $\left(V_{N 2}, V_{N s}\right)$ windings of input and output coupled inductance act as a voltage source and make a voltage loop with input dc source. As a result, these series voltage sources transfer energy to the load. Hence, the high voltage gain can be achieved by increasing of turn ratio of the coupled inductor. $C_{1}, C_{2}$ continues to store energy and then discharges this energy into the output inductance $V_{L m o}$ at the beginning of mode I. The presence of a secondary winding in the VM path increases the voltage across capacitor $C_{2}$ and transfers more energy to the output inductor when the switch is turned on. 

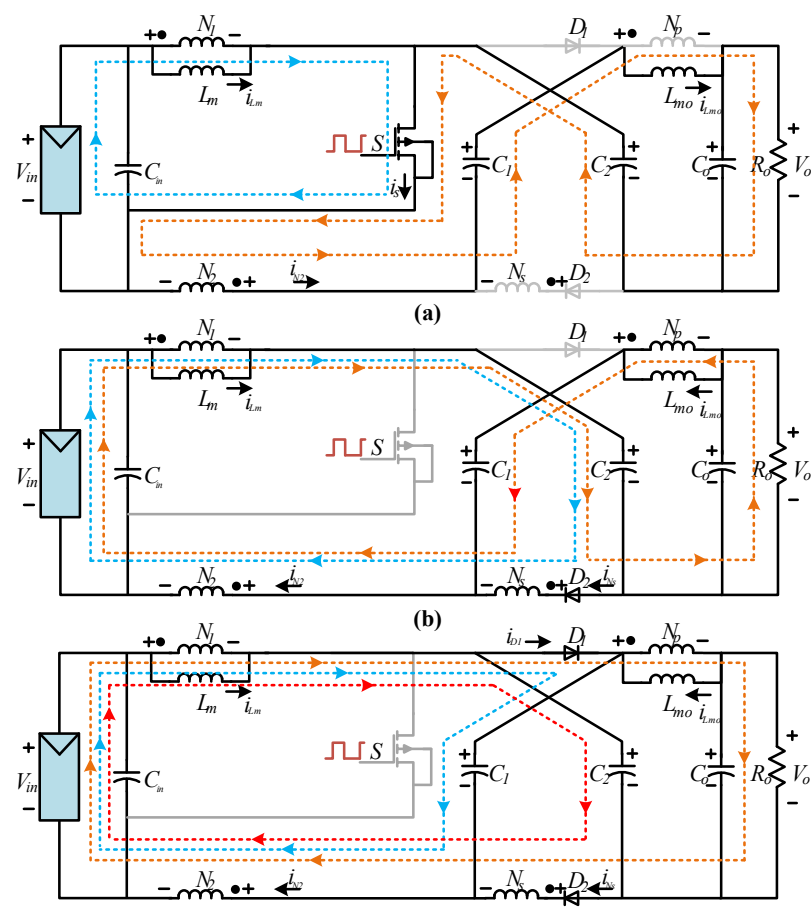

(c)

Fig. 3. Operational mode of the proposed converter a) Mode $I\left[t_{0}-t_{1}\right]$ b) Mode II(intermediate) $\left[\mathrm{t}_{1}-\mathrm{t}_{2}\right] \mathrm{c}$ ) Mode III $\left[\mathrm{t}_{2}-\mathrm{t}_{3}\right]$

\section{Equivalent Equations}

For optimizing the operation of the proposed topology, the converter design procedure is very important. Hence, the analysis of the proposed topology is discussed below.

\section{A. Calculation of the proposed converter voltage gain}

According to Fig. 3, the proposed converter has three modes in CCM condition. First, the below assumptions are considered.

$$
\begin{aligned}
& V_{N_{1}}=V_{L m}=\frac{N_{1}}{N_{2}} V_{N_{2}} \\
& V_{N p}=V_{L m o}=\frac{N_{p}}{N_{s}} V_{N_{s}} \\
& n_{i}=\frac{N_{2}}{N_{1}} \quad n_{o}=\frac{N_{s}}{N_{p}}
\end{aligned}
$$

where $V_{L m}$ and $V_{L m o}$ are the voltages of magnetizing inductances of primary and secondary coupled inductors. $n_{i}$ and $n_{o}$ are turn ratios of input and output coupled inductors respectively. By applying KVL law for mode I in Fig. 3(a), the following relations can be extracted :

$$
\begin{aligned}
& V_{L m}=V_{i n} \\
& V_{c 2}-V_{o}-V_{L m o}+V_{c 1}+n_{i} V_{L m}=0
\end{aligned}
$$

where $V_{c l}, V_{c 2}$ are voltages of $C_{1}$ and $C_{2}$ capacitors, respectively. When the first time interval is completed, the main switch goes to the turn-off state and diodes $D_{1}$ and $D_{2}$ is being to the conduction mode. However, it should be noted that the current of $D_{I}$ (MODE II) is equal to zero. KVL law for Fig. 3(b) and Fig. 3(c) are as follows:

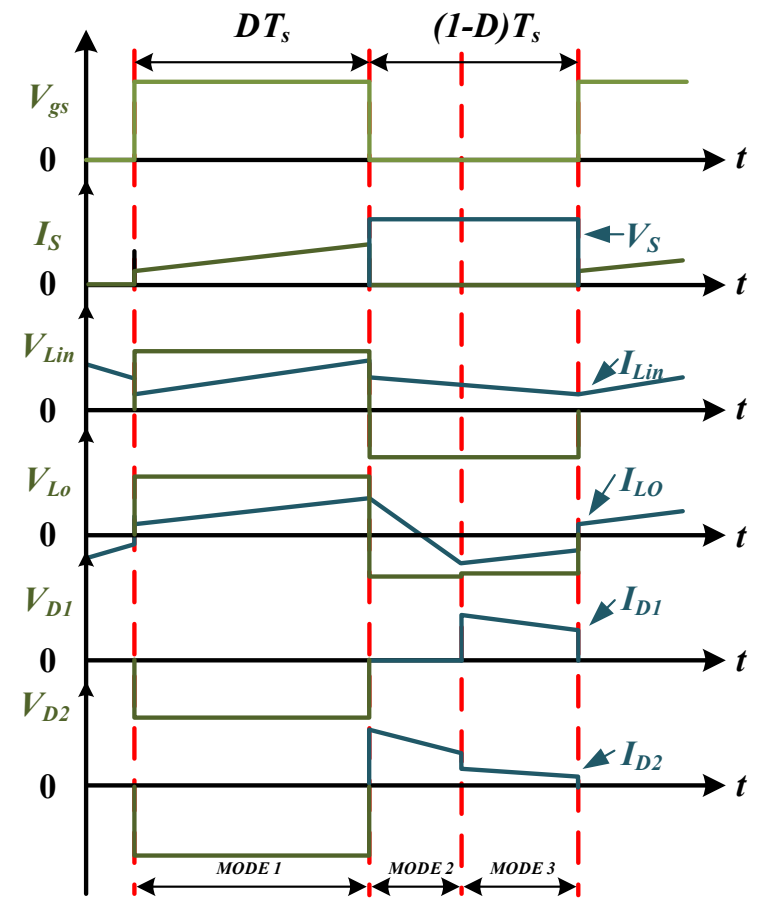

Fig. 4. Typical waveforms of the proposed converter

$$
\begin{aligned}
& -V_{i n}+V_{L m}+V_{L m o}+V_{o}+n_{o} V_{L m o}+n_{i} V_{L m}=0 \\
& -V_{i n}+V_{L m}+V_{c 1}+n_{i} V_{L m}=0 \\
& -V_{i n}+V_{L m}+V_{c 2}+n_{o} V_{L m o}+n_{i} V_{L m}=0 \\
& -V_{c 2}+V_{L m o}+V_{o}=0 \\
& -V_{c 1}+V_{c 2}+n_{o} V_{L m o}=0 \\
& -V_{c 1}+V_{L m o}+V_{o}+n_{o} V_{L m o}=0 \\
& -V_{i n}+V_{L m}+V_{c 2}-V_{o}-V_{L m o}+V_{c 1}+n_{i} V_{L m}=0
\end{aligned}
$$

In the $(1-D) T_{s}$ time interval, energy from the source as well as the energies stored in the windings of the coupled inductor are transferred to the load.

The $V_{c 1}$ and $V_{c 2}$ voltages of the proposed converter can be calculated according to the volt-second law of input inductor $L_{m}$ and output inductor $L_{m o}$ and respect to input and output voltages. Hence, considering equations (2) and (5):

$$
\begin{aligned}
& \left\{\begin{array}{l}
(2) \rightarrow V_{L m}=V_{i n} \\
(5) \rightarrow V_{L m}=\frac{(1-D)}{1+n_{i}}\left(V_{i n}-V_{c 1}\right)
\end{array}\right. \\
& D V_{i n}+\frac{(1-D)}{1+n_{i}}\left(V_{i n}-V_{c 1}\right)=0
\end{aligned}
$$

In (11), $D$ is the duty cycle of the active switch. As a result, $V_{c l}$ can be calculated as follows.

$$
V_{c 1}=\left(\frac{1+D n_{i}}{1-D}\right) V_{i n}
$$

By applying the volt-second law for output inductor $L_{m o}$ and based on (3) and (7), the below equation can be extracted. 


$$
\begin{aligned}
& \left\{\begin{array}{l}
(3) \rightarrow V_{L m o}=V_{c 2}-V_{o}+V_{c 1}+n_{i} V_{i n} \\
(7) \rightarrow V_{L m o}=V_{c 2}-V_{o}
\end{array}\right. \\
& D\left(V_{c 2}-V_{o}+V_{c 1}+n_{i} V_{\text {in }}\right)+(1-D)\left(V_{c 2}-V_{o}\right)=0
\end{aligned}
$$

The voltage of $C_{2}$ can be described from (13) as follows:

$$
V_{c 2}=V_{o}-D V_{c 1}-D n_{i} V_{i n}
$$

Finally, the output voltage gain can be calculated by applying volt-second law for the output inductor by using (3), (9), (12) and (14) as:

$$
\begin{aligned}
& \left\{\begin{array}{l}
(3) \rightarrow V_{L m o}=V_{c 2}-V_{o}+V_{c 1}+n_{i} V_{L m} \\
(9) \rightarrow V_{L m o}=\frac{V_{c 1}-V_{o}}{1+n_{o}}
\end{array}\right. \\
& D\left(V_{c 2}-V_{o}+V_{c 1}+n_{i} V_{L m}\right)+(1-D)\left(\frac{V_{c 1}-V_{o}}{1+n_{o}}\right)=0
\end{aligned}
$$

As a result, the output voltage gain of the proposed converter is calculated based on the below equation:

$$
M_{c c m}=\frac{V_{o}}{V_{i n}}=\frac{1+D+2 D n_{i}+D n_{o}+D n_{i} n_{o}}{1-D}
$$

Also, the output voltage gain by considering the leakage inductance is obtained from the following equation.

$$
M=\frac{V_{o}}{V_{\text {in }}}=\frac{1+D+2 D n_{i} k_{1}+n_{o} k_{2} D+n_{i} n_{o} k_{1} k_{2} D}{1-D}
$$

where $k_{1}$ and $k_{2}$ are magnetic coupling coefficients and calculated as follows.

$$
\begin{aligned}
& k_{1}=\frac{L_{m}}{L_{m}+L_{k 1}} \\
& k_{2}=\frac{L_{m o}}{L_{m o}+L_{k 2}}
\end{aligned}
$$

where $L_{m}, L_{k 1}, L_{m o}$ and $L_{k 2}$ are input magnetizing and leakage inductance and output magnetizing and leakage inductance respectively.

From (16), output voltage gain depends on three parameters $n_{i}$, $n_{o}$ and $D$. Hence, the output voltage of the proposed converter can be changed by adjusting any of the above parameters. This means that it has three degrees of design freedom for increasing output voltage gain.

Output voltage gain in terms of duty cycle and turn ratio of input coupled inductor $n_{i}=N_{2} / N_{1}$ is shown in Fig. 5. According to this figure, the proposed converter can achieve high voltage gain by increasing of $n_{i}$ turn ratio.

Output voltage gain versus of duty cycle and turn ratio of output coupled inductor $n_{o}=N_{s} / N_{p}$ is shown in Fig. 6. Similarly high voltage gain attains with increasing at output coupled inductor turn ratio. In the high step-up DC-DC converters, the output current is lower than the input current. Hence, increasing the number of turn ratio in the output coupled inductor effects less on reducing efficiency. By assuming that constant duty cycle $(D=0.5)$, the variation of output voltage gain concerning changing turn ratio at input and output coupled inductor is shown in Fig. 7.

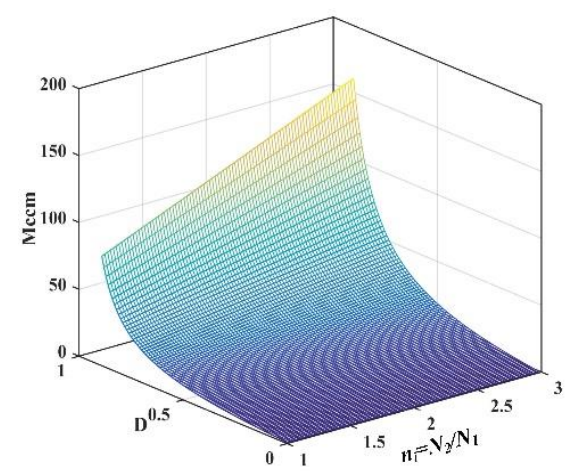

Fig. 5. Output voltage gain in terms of duty cycle and secondary winding of input inductor

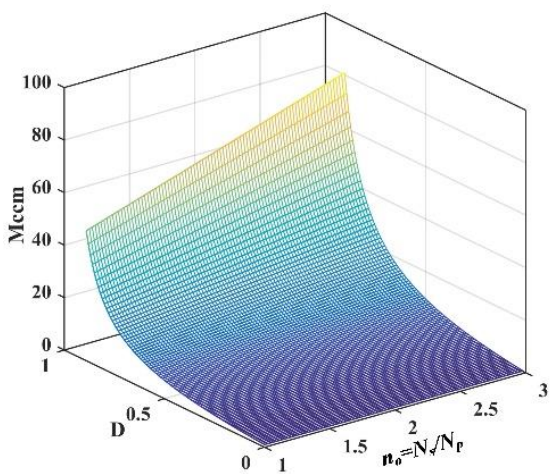

Fig. 6. Output voltage gain in terms of duty cycle and secondary winding of output inductor

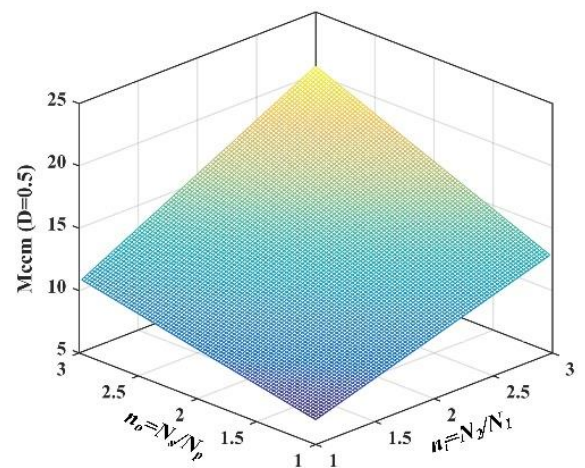

Fig. 7. Output voltage gain in terms of duty cycle and secondary winding of output inductor

\section{B. Voltage stresses of the semiconductors}

The proposed converter has one main switch and two diodes. The voltage across the semiconductor in the off state is used for stress calculation. Hence, the voltage at off state for the main active switch is equal to:

$$
V_{s}=V_{i n}-V_{L m}
$$

where $V_{s}$ is the voltage stress of the main active switch. Based on (2), when the active switch is turned on voltage of magnetizing inductance at the input coupled inductor is equal to the input voltage source. So, with applying volt-second law for input inductor and according to (2) and (20) the voltage stress of the main active switch can be obtained by: 


$$
\begin{aligned}
& D V_{\text {in }}+(1-D)\left(V_{\text {in }}-V_{s}\right)=0 \Rightarrow \\
& V_{s}=\frac{V_{\text {in }}}{1-D}
\end{aligned}
$$

Diodes, $D_{l}$ and $D_{2}$, are in blocking mode when the active switch is on. In $D T_{s}$ time interval, voltages of $D_{1}$ and $D_{2}$ can be calculated by the below equations.

$$
\begin{aligned}
& V_{D 1}+V_{c 1}+V_{L m}+n_{i} V_{L m}-V_{i n}=0 \\
& V_{D 2}+V_{o}+V_{L m o}+n_{o} V_{L m o}-V_{c 1}=0
\end{aligned}
$$

Using $V_{c l}$ and $V_{L m}$ from (5), the voltage of $D_{l}$ with accordance to (22) can be described as follows:

$$
V_{D 1}=-\frac{1+n_{i}}{1-D} V_{i n}
$$

Likewise, using $V_{c l}$ and $V_{\text {Lmo }}$ from (9) and substitution in (23) voltage of $D_{2}$ is calculated as:

$$
V_{D 2}=\frac{\frac{1+n_{o} D}{1-D}-M_{c c m}}{D} V_{i n}
$$

\section{Magnetizing inductances and core volume calculation}

First, magnetizing calculation of the proposed converter is investigated as follows. Based on [30] and [31], the magnetizing current of the coupled inductor is calculated as:

$$
I_{L m}=I_{1}+\frac{N_{2}}{N_{1}} I_{2}
$$

where $I_{L m}, I_{1}$ and $I_{2}$ are magnetizing currents, current of first winding and current of second winding respectively. According to (26) the average magnetizing current of input coupled inductor obtained as:

$$
I_{L m}=I_{i n}+\frac{N_{2}}{N_{1}} I_{o}=\left(M_{c c m}+n_{i}\right) I_{o}
$$

Also, the magnetizing current ripple for the input coupled inductor is calculated as follows:

$$
\Delta I_{L m}=I_{L m-\max }-I_{L m-\min }=\frac{D V_{\text {in }}}{L_{m} f_{s}}
$$

In the continuous conduction mode, the minimum current of the magnetizing inductor must be greater than zero. As a result, according to (27) and (28), the minimum required inductance for the input coupled inductor is derived from the below equation.

$$
L_{m}>\frac{R_{L} D}{2 M_{c c m}\left(n_{i}+M_{c c m}\right) f_{s}}
$$

Similarly, the average and ripple current of the magnetizing output inductance can be calculated as follows:

$$
\begin{aligned}
& I_{\text {Lmo }}=I_{o}+\frac{N_{s}}{N_{p}} I_{o}=\left(1+n_{o}\right) I_{o} \\
& \Delta I_{\text {Lmo }}=I_{\text {Lmo-max }}-I_{\text {Lmo-min }}=\frac{D(1+n i) V_{\text {in }}}{L_{m o} f_{s}}
\end{aligned}
$$

Considering equations (30) and (31), the minimum magnetizing inductance for the output coupled inductor can be described as follows.

$$
L_{m o}>\frac{R_{L} D\left(1+n_{i}\right)}{2 M_{c c m}\left(1+n_{o}\right) f_{s}}
$$

The area product $(A P)$ parameter will be calculated as an indicator of the required core volume in the converters. This parameter is the product of the window area, $W_{a}$, and the core cross-section, $A_{c}$. For the coupled inductor $A P$ is formulated as:

$$
A_{p_{-} \text {coupled }}=\frac{L_{11} I_{11}^{\max } \pm M_{12} I_{22}^{\max }}{B_{\max } k_{u} J} I_{r m s} \cdot 10^{4} \quad \mathrm{~cm}^{4}
$$

where $L_{11}, M_{12}, I_{11 \max }, I_{22 \max }, B_{\max }, k_{u}, J$ and $I_{r m s}$ are selfinductance, mutual inductance, the maximum current of first winding, the maximum current of second winding, the maximum flux density of the core, winding fill factor, current density and RMS current of winding respectively. Mutual inductance can be obtained as:

$$
M_{12}=k \sqrt{L_{11} L_{22}}
$$

where $k$ is the coupling coefficient.

\section{Efficiency Analysis}

In this section, the detailed loss analysis among components of the proposed converter is investigated. Losses in DC-DC converters are divided into different parts including switching losses, diode losses, magnetic losses and capacitive losses. Hence, the loss distribution among components of the proposed converters is studied using the analytical method presented in [31]-[35].

1) Mosfet Switch loss

The conduction loss of the Mosfet is obtained as follows:

$$
P_{\text {mosfet_cond }}=R_{D S_{-} \text {on }} I_{r m s}^{2}
$$

where $R_{D S}$ on and $I_{r m s}$ are the on-resistance of the Mosfet during its on-state and RMS of Mosfet current respectively.

The switching loss of the Mosfet is obtained as:

$$
P_{\text {mosfet_switching }}=\frac{1}{2} C_{s} f_{s w} V_{S}^{2}
$$

where $C_{s}$ is the output capacitance of the active power switch which is derived from the Mosfet datasheet. Also, $f_{s w}$ and $V_{s}$ are the switching frequency and the off-state voltage across the power switch.

2) Diode loss

The conduction loss of diodes is calculated from (37), where, $V_{D_{-} \text {on }}, R_{D_{-} \text {on }}, I_{D_{-} \text {avg }}$ and $I_{D_{-} r m s}$ are the diode on-state voltage drop, on-resistance of the diode, average and RMS diode currents, respectively.

$$
P_{D_{-} \text {con }}=V_{D_{-} o n} I_{D_{-} a v g}+R_{D_{-} \text {on }} I_{D_{-} r m s}^{2}
$$

3) Magnetic core and copper loss

According to [32], magnetic core loss per $\mathrm{kg}$ is obtained as,

$$
P_{\text {core_loss }}=K_{c}\left(\frac{\Delta B}{2}\right)^{\beta} f_{s w}^{\alpha} \quad\left(\frac{w}{m^{3}}\right)
$$

where $K_{c}, \alpha$ and $\beta$ are constants relating to the magnetic core material, which are given in [32] for the selected core material. Also, $\Delta B$ is peak to peak flux density ripple. In addition, the copper loss of the windings of the coupled-inductors are formulated in [34] as,

$$
P_{\text {copper_loss }}=\rho \frac{M L T}{K_{u} W_{a}}\left(N_{1} I_{1}+N_{2} I_{2}\right)^{2}
$$


where, $\rho, M L T, W a, K u$ are the copper wire resistivity, the mean length per turn of windings, the winding area of the core and the winding fill factor, respectively. Also, $N_{l}$ and $\mathrm{N}_{2}$ (or $N_{p}, N_{s}$ ) are windings turns, and $I_{N 1}, I_{N 2}$ (or $I_{N p}, I_{N S}$ ) are RMS currents of windings.

4) Capacitor ESR loss

The capacitor loss is associated with the equivalent series resistance (ESR) of the capacitor, which can be experimentally measured. This power loss is obtained as,

$$
P_{\text {capacitor_loss }}=R_{E S R} I_{c}^{2}
$$

where, $R_{E S R}$ and $I_{c}$ are the equivalent series resistance and the RMS current of the capacitor, respectively. All capacitors losses are calculated using (40) and summed together as the total loss of the capacitors.

\section{COMPARISON STUDY}

In this part, a brief comparison is done between the proposed converter and other high step-up DC-DC converters. The focus of this comparison is around the number of components such as switches, diodes, inductors and capacitors and also voltage stresses of semiconductors and voltage gain. This comparison is collected in Table. I, in which, the number of capacitors regardless of the output capacitor is calculated. The proposed converter has lower components with respect to all HSUT DCDC topologies in Table. I.

In order to explore the voltage gain variation versus duty cycle, in three different modes by changing the turn ratio of coupled inductor is shown in Fig. 8. Both [16], [36] use a VMC circuit but they have a fixed gain as shown in Fig. 8. Moreover, in [36] utilizing two active switches leads to increase complexity and conduction loss. From Fig. 8 (a) with a duty cycle below 0.5 , the converters in [18], [27], [37] have a higher gain than the proposed topology. It should be mentioned that these converters contain more diodes and capacitors which leads to decrease efficiency and lifetime respectively.

Based on Fig. 8 (b), (c), if the turn ratio of the coupled inductor increases, the voltage gain of the proposed converter becomes more distant from other converters. It should be noted that, contrary to [18], [25], [27] and [38], the ratio of the coupled inductor is equal to the primary to the secondary ratio in the proposed converter. Therefore, the turn ratio of the coupled inductor must be raised for increasing the voltage gain. As a result, the turn ratio of the primary winding is greater than the turn ratio of the secondary winding in those converters that leads to high magnetizing inductance, and consequently higher size and losses in the coupled inductor.

In another comparison, total voltage stresses (TVS) for the active switch and diode with respect to changing the turn ratio of the coupled inductor is investigated. The voltage gain is considered fixed and equal to $12(\mathrm{~g}=12)$. Based on Fig. 9 and Fig. 10, the TVS for the active switch and diodes are grid shape and other topologies are single line. From Fig. 9, it can be seen that there are many choices for ni and no in order to achieve low TVS for the active switch in the proposed topology.

Moreover, the TVS for the active switch is less than [16], [18], [25], [27], [36] and [37] which leads to the size and cost reduction of the active switch. In some points of Fig. 9, with the increasing turn ratio of the coupled inductor, the TVS of the active switch of [38] is below than proposed topology.

However, in [38] increasing the turn ratio leads to a high magnetizing current and more core size. Another comparison is related to the TVS of diodes, which is shown in Fig. 10. In this figure, the TVS for the diode in the proposed topology is mainly lower than other HSUT converters. Also, g=12 can be achieved with different values of $n_{i}$ and $n_{o}$ to reduce TVS for diodes. As a result, high step-up gain along with low switch stress is accessible in the proposed converter.

Table. I. Comparison between the proposed topology and other high step-up topologies

\begin{tabular}{|c|c|c|c|c|c|c|c|c|}
\hline & \multirow[t]{2}{*}{ Voltage Gain(M) } & \multirow{2}{*}{$\begin{array}{c}\text { Switch } \\
\text { Voltage } \\
\text { Stress } \sum V_{S}\end{array}$} & \multirow[t]{2}{*}{ Diode Voltage Stress $\sum V_{d}$} & \multicolumn{4}{|c|}{$\begin{array}{l}\text { Number of } \\
\text { components }\end{array}$} & \multirow{2}{*}{$\begin{array}{c}\text { Total of } \\
\text { Components }\end{array}$} \\
\hline & & & & SW & $\mathrm{D}$ & $\mathrm{C}$ & Core & \\
\hline $\begin{array}{l}\text { Converter } \\
\text { in [27] }\end{array}$ & $\frac{2+n+D}{1-D} \quad n: N_{p} / N_{s}$ & $\frac{1+M}{3+n} V_{I}$ & $\frac{(2 n+4)(1+M)}{3+n} V_{I}$ & 1 & 4 & 4 & 2 & 9 \\
\hline $\begin{array}{l}\text { Converter } \\
\text { in [37] }\end{array}$ & $\frac{2+n+D(n+1)}{1-D} \quad n: N_{s} / N_{p}$ & $\frac{1+M+n}{3+2 n} V_{I}$ & $\frac{(3 n+4)(1+M+n)}{3+2 n} V_{I}$ & 1 & 4 & 4 & 2 & 9 \\
\hline $\begin{array}{l}\text { Converter } \\
\text { in [38] }\end{array}$ & $\frac{(n+1) D+1}{1-D}+2 n \quad n: N_{p} / N_{s}$ & $\frac{M-n+1}{n+2} V_{I}$ & $\frac{(3 n+1)(M+1-n)}{n+2} V_{I}$ & 1 & 4 & 4 & 2 & 9 \\
\hline $\begin{array}{l}\text { Converter } \\
\text { in [16] }\end{array}$ & $\frac{3+D}{2(1-D)}$ & $\frac{1+2 M}{4} V_{I}$ & $\frac{(3+6 M)}{4} V_{I}$ & 1 & 4 & 3 & 2 & 8 \\
\hline $\begin{array}{l}\text { Converter } \\
\text { in [36] }\end{array}$ & $\frac{3+D}{1-D}$ & $\frac{2(1+M)}{3} V_{I}$ & $1.5(M+1) V_{I}$ & 2 & 3 & 2 & 3 & 6 \\
\hline $\begin{array}{l}\text { Converter } \\
\text { in }[18]\end{array}$ & $\frac{2(n+1)}{1-D} n: N_{p} / N_{s}$ & $\frac{M}{1+n} V_{I}$ & $\frac{7 M}{1+n} V_{I}$ & 2 & 7 & 6 & 2 & 15 \\
\hline $\begin{array}{l}\text { Converter } \\
\text { in }[25]\end{array}$ & $\frac{(n+1)}{1-D} n: N_{p} / N_{s}$ & $\frac{M}{n+1} V_{I}$ & $\frac{(2 n+1) M}{n+1} V_{I}$ & 1 & 3 & 3 & 2 & 7 \\
\hline $\begin{array}{l}\text { Proposed } \\
\text { converter }\end{array}$ & $\begin{array}{c}\frac{1+D+2 D n_{i}+D n_{o}+D n_{i} n_{o}}{1-D} \\
n_{i}:{ }^{N_{2}} / N_{1} n_{o}: N_{s} / N_{p} \\
A=\frac{M+1+2 n i+n o+n i n o}{2+2 n i+n o+n o n i}\end{array}$ & $A V_{I}$ & $A\left(2+3 n_{i}+n_{i} n_{o}\right) V_{I}$ & 1 & 2 & 2 & 2 & 5 \\
\hline
\end{tabular}




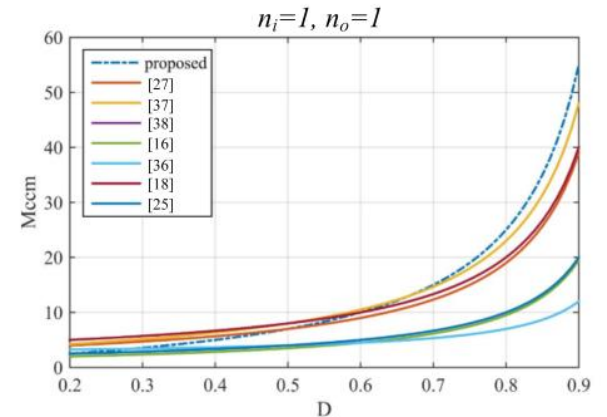

(a)

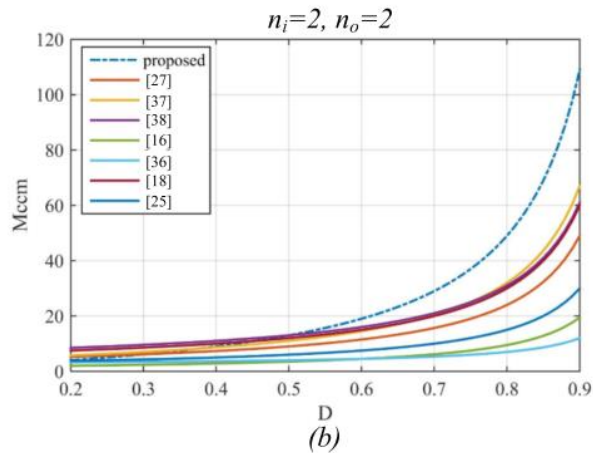

(b)

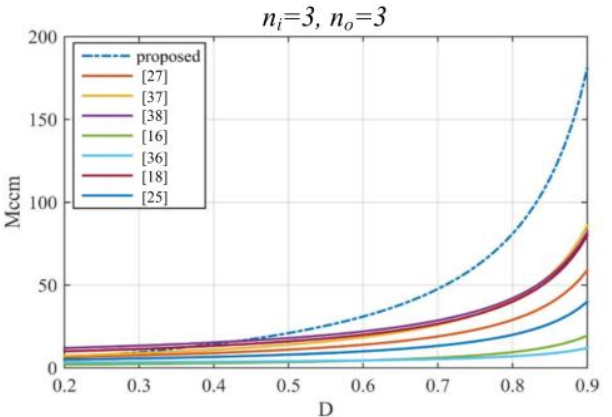

(c)

Fig. 8. Gain versus $d$ in the proposed converter and other high step-up converters a) $n_{i}=n_{o}=1$ b) $n_{i}=n_{o}=2$ c) $n_{i}=n_{o}=3$

Total switches voltage stress $(g=12)$

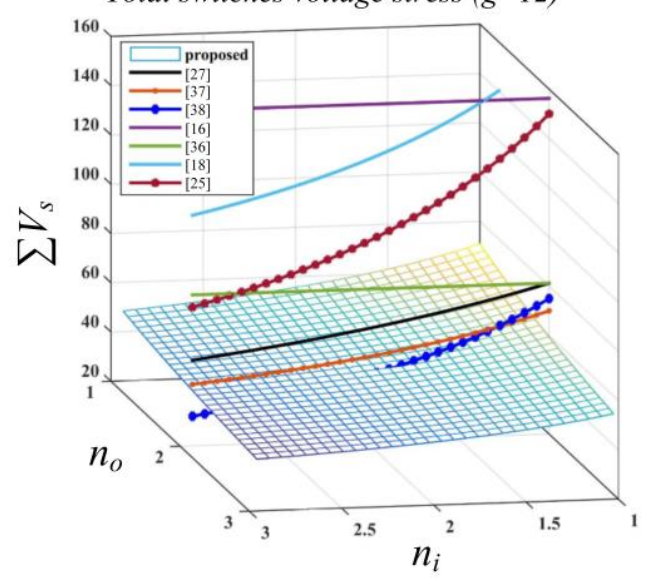

Fig. 9. Switch stress versus gain for the proposed converter and other high step-up converters

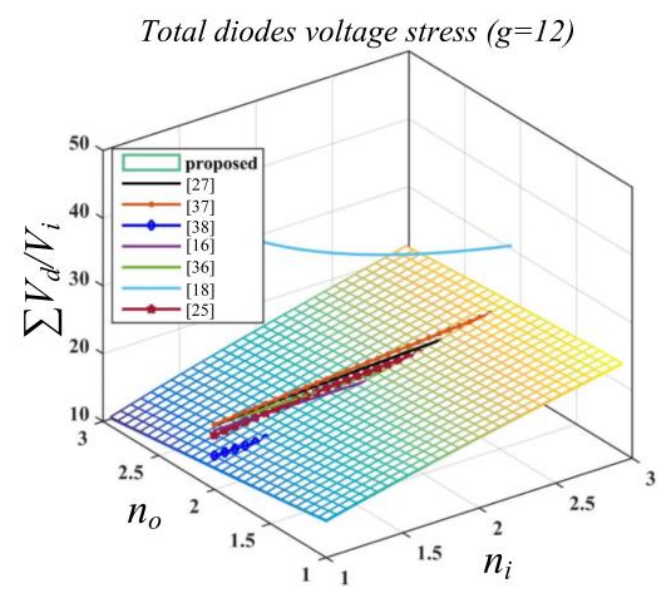

Fig. 10. Diodes stress versus gain the proposed converter and other high stepup converters

\section{V.EXPERIMENTAL RESULTS}

A 200-watt prototype of the proposed converter was built and several tests have been done to evaluate its performance. The experimental setup of the proposed converter is shown in Fig. 11. The parameters of the experimental setup have been designed in accordance with the aforementioned equations and are stated in Table. II. For this evaluation, the duty cycle is considered around 0.65 and coupled inductors turn ratio is equal to $1: 1$. Total loss in the proposed topology with 4 different turn ratios of the coupled inductor is shown in Fig. 12. It can be seen that using a greater turn ratio of the coupled inductors leads to higher output voltage gain. On the other hand, the losses are increased as well as the efficiency is decreased in the proposed converter with higher turn ratios. Output voltage along with input voltage and current are shown in Fig. 13. The output voltage is equal to $300 \mathrm{~V}$ with $25 \mathrm{~V}$ input voltage, and the voltage gain corresponds to 12 .

From Fig. 13, it can be seen that high output voltage is achieved with a middle duty cycle. In the theoretical analysis with the $\mathrm{D}=0.65$, voltage gain equals 12.14 which has an acceptable difference with the experimental gain due to the voltage drop of the semiconductors and winding resistance.

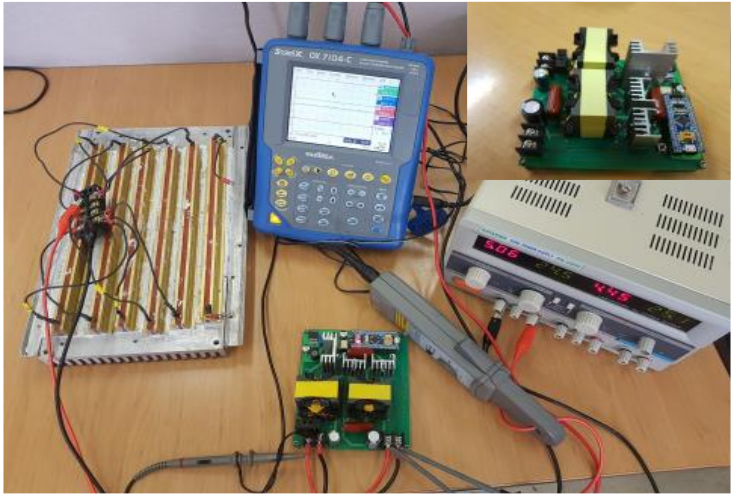

Fig. 11. The experimental setup of the proposed high step-up DC-DC converter

Table. II. Parameters of the proposed converter

\begin{tabular}{c|c}
\hline \hline Parameters & Value \\
\hline \hline Input Voltage $\left(V_{i n}\right)$ & $25 \mathrm{~V}$ \\
Output Voltage $\left(V_{o}\right)$ & $300 \mathrm{~V}$ \\
Output Power $\left(P_{o u t}\right)$ & $200 \mathrm{~W}$ \\
Output Capacitor $\left(C_{o}\right)$ & $56 \mu \mathrm{F}$ \\
Magnetizing Inductance of $L_{m}$ & $30 \mu \mathrm{H}$ \\
Magnetizing Inductance of $L_{m o}$ & $400 \mu \mathrm{H}$ \\
Turn Ratio for $n_{i}$ and $n_{o}$ & $N_{2} / N_{l}=N_{s} / N_{p}=1$ \\
Power Switch & IRFP260 \\
Diodes $\left(D_{1}, D_{2}\right)$ & MUR2040, MBR20200 \\
VMC Capacitors $\left(C_{l}, C_{2}\right)$ & $2.2 \mu \mathrm{F}$ \\
Load Resistance $\left(R_{o}\right)$ & $450 \Omega$ \\
Switching Frequency $\left(f_{s w}\right)$ & $75 \mathrm{kHz}$ \\
\hline \hline
\end{tabular}




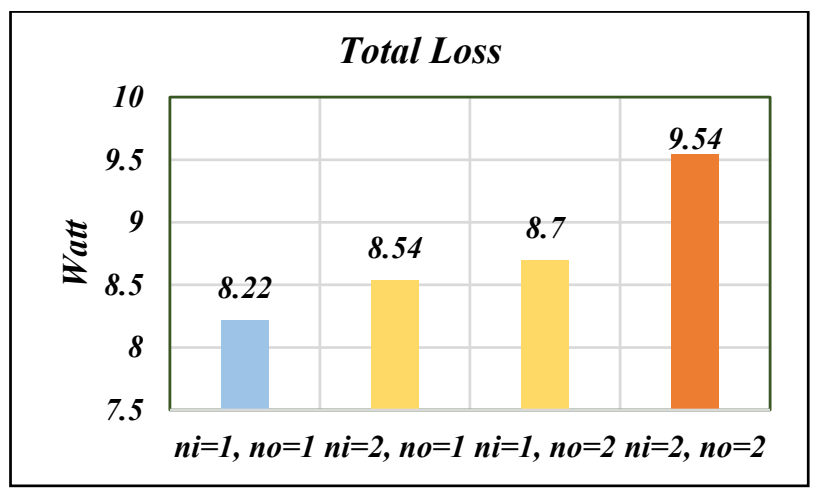

Fig. 12. Total power loss of the proposed topology with various winding turn ratios of the coupled-inductor

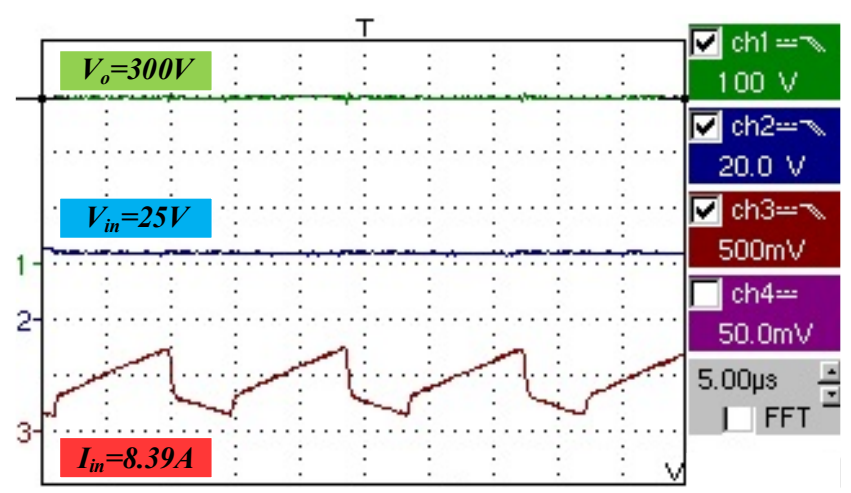

Fig. 13. Experimental result of the proposed converter 1:Output voltage 2: Input voltage 3:Input current

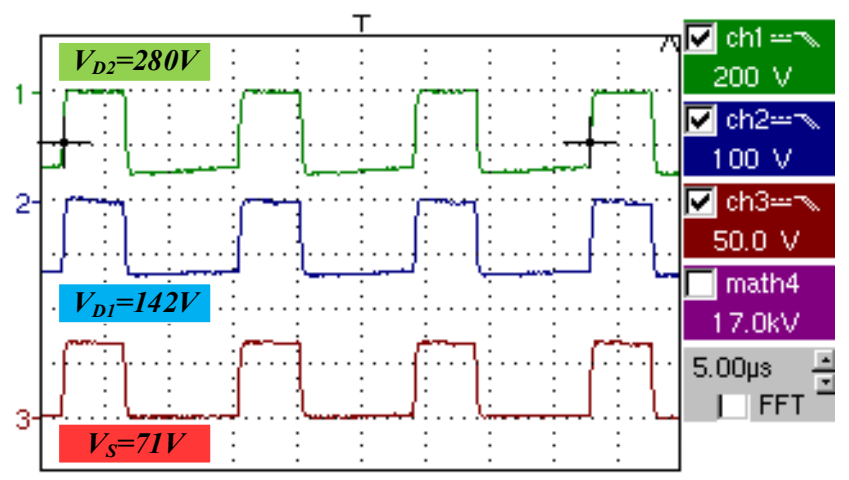

Fig. 14. Experimental result of the proposed converter 1: $D_{2}$ voltage 2: $D_{1}$ voltage 3: Switch voltage

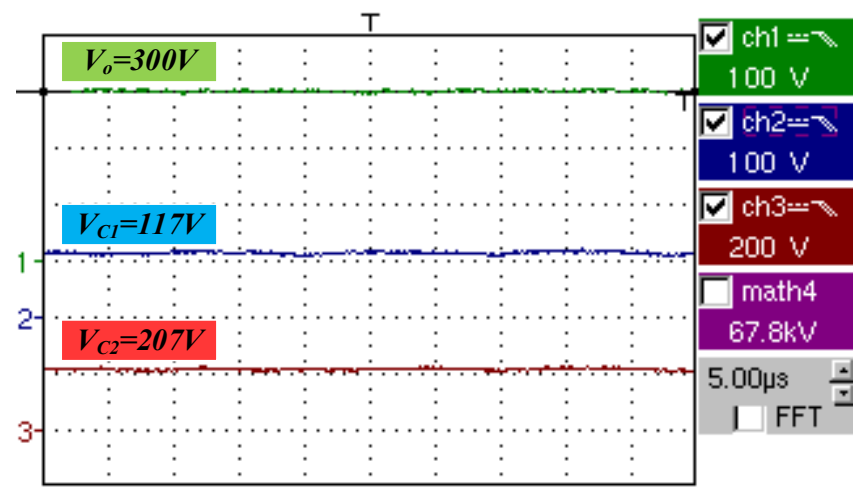

Fig. 15. Experimental result of the proposed converter 1: Output voltage 2: $C_{1}$ voltage 3: $C_{2}$ voltage

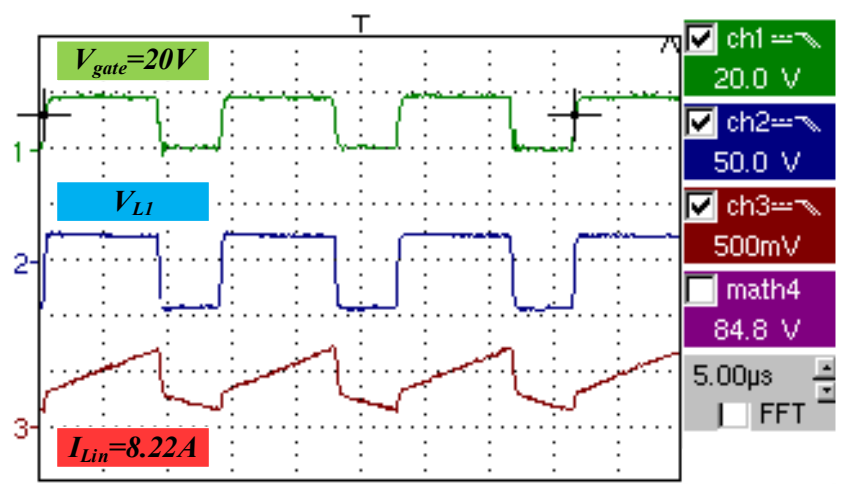

Fig. 16. Experimental result of the proposed converter 1: Gate signal 2: Output inductor voltage 3 : Output inductor current

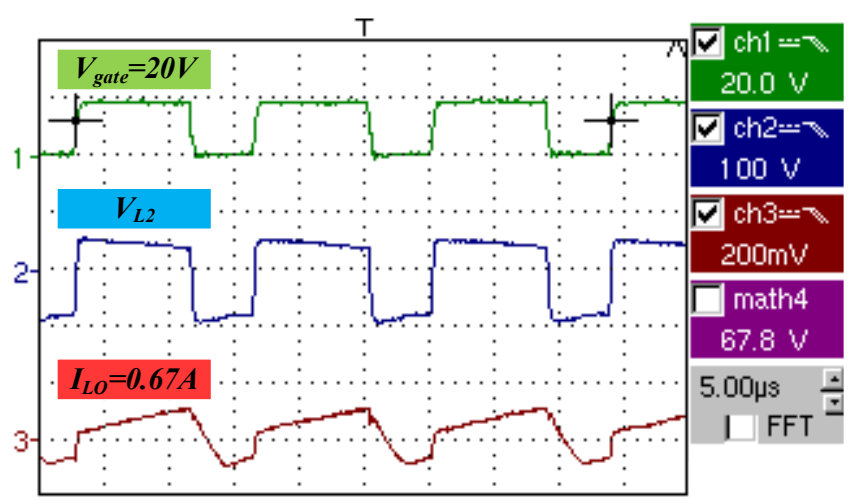

Fig. 17. Experimental result of the proposed converter: 1) Gate signal, 2) Input inductor voltage, 3) Input inductor current.

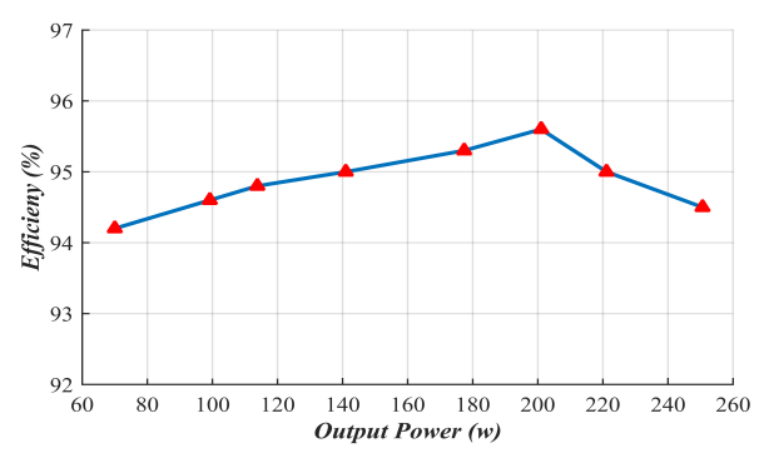

Fig. 18. Efficiency versus output power

The output power of the proposed converter is equal to $200 \mathrm{~W}$ and the efficiency corresponds to $95.6 \%$. for $8.3 \mathrm{~A}$ input current. The voltage stress of the power switch and VM diodes are shown in Fig. 14. According to this figure, the voltage stress of the switch is around $71 \mathrm{~V}$ which is considerably low compared to the output voltage. Hence, a switch with low voltage can be used that has a low on-resistance $\left(R_{D S-o n}\right)$. As a result, the conduction loss of the switch is low that leads to an increase in the efficiency of the proposed topology. Also, the voltage stresses of the VM diodes $D_{l}$ and $D_{2}$ are shown in Fig. 14. The voltage stress of diode $D_{1}$ is $142 \mathrm{~V}$ and the voltage stress of diode $\mathrm{D} 2$ is $280 \mathrm{~V}$ which are closed to equations (24) and (25), respectively. As can be seen from Fig. 15, the voltages of capacitors $C_{I}$ and $C_{2}$ along with output voltage are depicted. The voltage ripples of these capacitors are low. Moreover, the value 
of $V_{c l}$ is $117 \mathrm{~V}$ and the value of $V_{c 2}$ is $207 \mathrm{~V}$ which correspond to equations (12) and (14), respectively.

Finally, the gate pulse along with magnetizing voltage and current of the input and output coupled inductors are shown $\mathrm{i}$

Fig. 16 and Fig. 17, respectively. In the turn-on state of the active switch, the current is increased among both coupled inductors. Also, the magnetizing inductance current is decreasing and discharging its saved energy into the circuit elements at the off state.

The efficiency while power increases from $70 \mathrm{w}$ to $250 \mathrm{w}$ is shown in Fig. 18. In the beginning, when the output power changes between $70 \mathrm{w}$ to $200 \mathrm{w}$, the efficiency of the proposed converter is increased. The peak efficiency occurs at the $200 \mathrm{~W}$ output power and its value is equal to $95.6 \%$. Then, the efficiency is decreased due to the domination of copper and switching loss. However, in the proposed topology efficiency always is higher than $94 \%$ at all output power from $70 \mathrm{~W}$ to $250 \mathrm{~W}$. The breakdown loss of the proposed converter is shown in Fig. 19, and it can be seen that the prevailing power loss is related to the power switch.

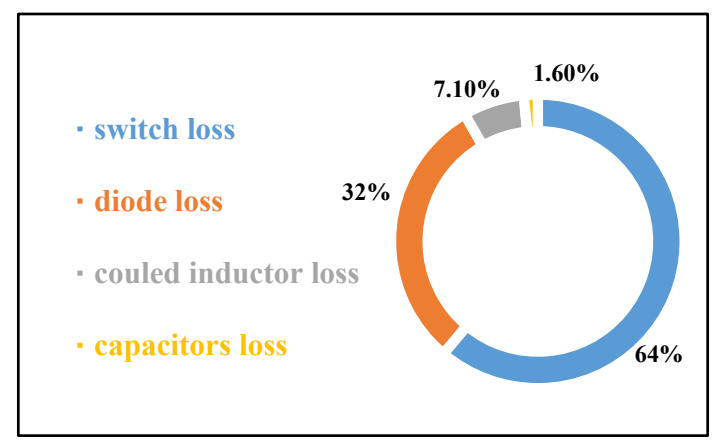

Fig. 19. Breakdown loss of the proposed converter

\section{CONCLUSION}

In this paper, a new topology of a high step-up transformerless DC-DC converter with a voltage multiplier coupled inductor was introduced. The proposed converter consists of one modified boost converter and a new voltage multiplier structure. Voltage gain can be increased with an appropriate turn ratio of the CLs. The steady-state performance under the CCM condition has been presented. The total voltage stress of the active switches is decreased compared to other high step-up DC-DC converters. High voltage gain, low switching stress, three degrees of design freedom and uses of a single power switch are the significant advantages of the proposed topology. The experimental results were performed to evaluate theoretical analysis wherein high voltage gain 12 was obtained under 95.6\% efficiency. Experimental results show high voltage gain along with low switching stress for the proposed topology.

\section{REFERENCES}

T. Jalilzadeh, N. Rostami, E. Babaei, and M. Maalandish, "Ultra-stepup dc-dc converter with low-voltage stress on devices," IET Power Electronics, vol. 12, no. 3, pp. 345-357, Mar. 2019.

[2] S. B. Kjaer, J. K. Pedersen, and F. Blaabjerg, "A Review of SinglePhase Grid-Connected Inverters for Photovoltaic Modules," IEEE
Transactions on Industry Applications, vol. 41, no. 5, pp. 1292-1306, Sep. 2005.

[3] M. Obi and R. Bass, "Trends and challenges of grid-connected photovoltaic systems - A review," Renewable and Sustainable Energy Reviews, vol. 58, pp. 1082-1094, 2016.

[4] R. Dogga and M. K. Pathak, "Recent trends in solar PV inverter topologies," Solar Energy, vol. 183, no. February, pp. 57-73, 2019.

[5] W. Li and X. He, "Review of Nonisolated High-Step-Up DC/DC Converters in Photovoltaic Grid-Connected Applications," IEEE Transactions on Industrial Electronics, vol. 58, no. 4, pp. 1239-1250, Apr. 2011.

6] W. J. Cha, Y. W. Cho, J.-M. Kwon, and B. H. Kwon, "High Efficient Micro-inverter with Soft-switching Step-up Converter and Singleswitch-modulation Inverter," IEEE Transactions on Industrial Electronics, pp. 1-1, 2014.

[7] A. Ajami, H. Ardi, and A. Farakhor, "A Novel High Step-up DC/DC Converter Based on Integrating Coupled Inductor and SwitchedCapacitor Techniques for Renewable Energy Applications," IEEE Transactions on Power Electronics, vol. 30, no. 8, pp. 4255-4263, Aug. 2015.

[8] M. Muhammad, M. Armstrong, and M. A. Elgendy, "A Nonisolated Interleaved Boost Converter for High-Voltage Gain Applications," IEEE Journal of Emerging and Selected Topics in Power Electronics, vol. 4, no. 2, pp. 352-362, Jun. 2016.

C. G. Zogogianni, E. C. Tatakis, and V. Porobic, "Investigation of a Non-isolated Reduced Redundant Power Processing DC/DC Converter for High-Power High Step-Up Applications," IEEE Transactions on Power Electronics, vol. 34, no. 6, pp. 5229-5242, Jun. 2019.

B. Gu et al., "High Reliability and Efficiency Single-Phase Transformerless Inverter for Grid-Connected Photovoltaic Systems," vol. 28, no. 5, pp. 2235-2245, 2013.

T. Yan, J. Xu, F. Zhang, J. Sha, and Z. Dong, "Variable On-Time Controlled Critical Conduc- tion Mode Flyback PFC Converter," vol. 62, no. 6, 2014.

J. Roy, Y. Xia, and R. Ayyanar, "High Step-Up Transformerless Inverter for AC Module Applications with Active Power Decoupling," IEEE Transactions on Industrial Electronics, vol. 66, no. 5, pp. 3891-3901, 2019.

H. Liu et al., "A Family of High Step-Up Coupled-Inductor Impedance-Source Inverters With Reduced Switching Spikes," IEEE Transactions on Power Electronics, vol. 33, no. 11, pp. 9116-9121, Nov. 2018.

[14] M. Forouzesh, Y. P. Siwakoti, S. A. Gorji, F. Blaabjerg, and B. Lehman, "Step-Up DC-DC converters: A comprehensive review of voltage-boosting techniques, topologies, and applications," IEEE Transactions on Power Electronics, vol. 32, no. 12, pp. 9143-9178, 2017.

[15] Y. Wang, Y. Qiu, Q. Bian, Y. Guan, and D. Xu, "A Single Switch Quadratic Boost High Step Up DC-DC Converter," IEEE Transactions on Industrial Electronics, vol. 66, no. 6, pp. 4387-4397, 2019.

[16] S. Saravanan and N. R. Babu, "Design and Development of Single Switch High Step-Up DC-DC Converter," IEEE Journal of Emerging and Selected Topics in Power Electronics, vol. 6, no. 2, pp. 855-863, Jun. 2018.

[17] K. B. Park, G. W. Moon, and M. J. Youn, "Nonisolated high step-up stacked converter based on boost-integrated isolated converter," IEEE Transactions on Power Electronics, vol. 26, no. 2, pp. 577-587, 2011.

[18] M. L. Alghaythi, R. M. O'Connell, N. E. Islam, M. M. S. Khan, and J. M. Guerrero, "A High Step-Up Interleaved DC-DC Converter with Voltage Multiplier and Coupled Inductors for Renewable Energy Systems," IEEE Access, vol. 8, pp. 123165-123174, 2020.

[19] Y.-C. Lim, M.-K. Nguyen, and J.-H. Choi, "Two switched-inductor quasi-Z-source inverters," IET Power Electronics, vol. 5, no. 7, pp. 1017-1025, 2012.

[20] X. Xing, A. Chen, W. Wang, C. Zhang, Y. Li, and C. Du, "Spacevector-modulated for Z-source three-level T-type converter with neutral voltage balancing," in 2015 IEEE Applied Power Electronics Conference and Exposition (APEC), pp. 833-840, 2015.

[21] F. Faraji, S. M. M. Mousavi G., A. Hajirayat, A. A. M. Birjandi, and K. Al-Haddad, "Single-stage single-phase three-level neutral-pointclamped transformerless grid-connected photovoltaic inverters: 
Topology review," Renewable and Sustainable Energy Reviews, vol. 80, no. April, pp. 197-214, Dec. 2017.

[22] A. Samadian, S. H. Hosseini, M. Sabahi, and M. Maalandish, "A New Coupled Inductor Nonisolated High Step-Up Quasi Z-Source DC-DC Converter," IEEE Transactions on Industrial Electronics, vol. 67, no. 7, pp. 5389-5397, 2020.

[23] B. Wu, S. Li, K. Ma Smedley, and S. Singer, "A Family of TwoSwitch Boosting Switched-Capacitor Converters," IEEE Transactions on Power Electronics, vol. 30, no. 10, pp. 5413-5424, Oct. 2015.

[24] M. D. Seeman and S. R. Sanders, "Analysis and Optimization of Switched-Capacitor DC-DC Converters," IEEE Transactions on Power Electronics, vol. 23, no. 2, pp. 841-851, Mar. 2008.

[25] S. Pourjafar, F. Sedaghati, H. Shayeghi, and M. Maalandish, "High step-up DC-DC converter with coupled inductor suitable for renewable applications," IET Power Electronics, vol. 12, no. 1, pp. 92-101, Jan. 2019

[26] J. Ai, M. Lin, and M. Yin, "A Family of High Step-Up Cascade DCDC Converters with Clamped Circuits," IEEE Transactions on Power Electronics, vol. 35, no. 5, pp. 4819-4834, 2020.

[27] R. Moradpour, H. Ardi, and A. Tavakoli, "Design and Implementation of a New SEPIC-Based High Step-Up DC/DC Converter for Renewable Energy Applications," IEEE Transactions on Industrial Electronics, vol. 65, no. 2, pp. 1290-1297, Feb. 2018.

[28] S. W. Lee and H. L. Do, "Quadratic Boost DC-DC Converter with High Voltage Gain and Reduced Voltage Stresses," IEEE Transactions on Power Electronics, vol. 34, no. 3, pp. 2397-2404, 2019.

[29] E. H. Ismail et al., "A Family of Single-Switch PWM Converters With High Step-Up Conversion Ratio," IEEE Transactions on Circuits and Systems I: Regular Papers, vol. 55, no. 4, pp. 11591171, May 2008.

[30] A. H. Masoumi, S. Sharifi, M. Monfared, and M. S. Karbasforooshan, " $\Gamma$-Source Magnetic Integrated Filter for Single-Phase Grid Tied Voltage Source Converters," IEEE Trans. Ind. Electron., vol. 67, no. 7, pp. 5410-5420, 2020.

[31] C. W. Mclyman, Transformer and Inductor Design Handbook. Boca Raton, FL, USA: CRC Press, 2011.

[32] W. G. Hurley and W.H. Wölfle, Transformers and Inductors for Power Electronics: Theory, Design and Applications. John Wiley \& Sons, Apr 29, 2013.

[33] D. Graovac, M. Pürschel and A. Kiep "Mosfet Power Losses Calculation U sing the Data-Sheet Parameters," Infineon, App. Note, 2006.

[34] M. K. Nguyen, Y. C. Lim, and S. J. Park, "Improved trans-Z-source inverter with continuous input current and boost inversion capability," IEEE Trans. Power Electron., vol. 28, no. 10, pp. 45004510, 2013.

[35] Y. Wang, Y. Qiu, Q. Bian, Y. Guan, and D. Xu, "A Single Switch Quadratic Boost High Step Up DC-DC Converter," IEEE Transactions on Industrial Electronics, vol. 66, no. 6, pp. 4387-4397, 2019.

[36] M. A. Salvador, J. M. De Andrade, T. B. Lazzarin, and R. F. Coelho, "Nonisolated high-step-up DC-DC converter derived from switchedinductors and switched-capacitors," IEEE Transactions on Industrial Electronics, vol. 67, no. 10, pp. 8506-8516, 2020.

[37] H. Ardi and A. Ajami, "Study on a High Voltage Gain SEPIC-Based DC-DC Converter with Continuous Input Current for Sustainable Energy Applications," IEEE Transactions on Power Electronics, vol. 33, no. 12, pp. 10403-10409, Dec. 2018.

[38] S. Hasanpour, A. Baghramian, and H. Mojallali, "A Modified SEPICBased High Step-Up DC-DC Converter with Quasi-Resonant Operation for Renewable Energy Applications," IEEE Transactions on Industrial Electronics, vol. 66, no. 5, pp. 3539-3549, May 2019.

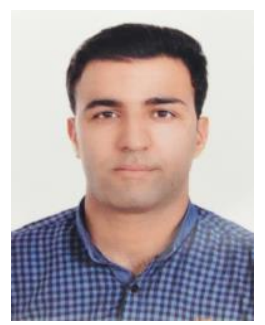

Pouria Sarvghadi was born in Mashhad, Iran, in 1990. He received the B.Sc. degree in power electrical engineering from the Sadjad University, Mashhad, Iran, in 2013. He also received his M.Sc. degree (with honor) at power electronics from Ferdowsi University of Mashhad, Iran, in 2017. He is currently working toward the Ph.D. degree in electrical engineering at the Department of Electrical and Computer Engineering, Tarbiat Modares University of Tehran, Iran, since 2017. His research interests include high step-up dcdc converter, renewable energy, DC-AC Converter, designing and controlling of power electronic converters.

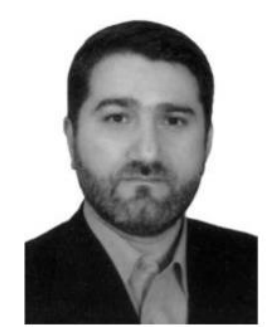

Ali Yazdian Varjani (M'95) was born in Tehran, Iran in 1965. He received his B.Sc. from the Sharif University of Technology in 1989, and his M.Eng. and Ph.D. in electrical engineering from the University of Wollongong, Australia, in 1995 and 1999, respectively. Since 1999 , he has been with Tarbiat Modares University, Tehran, Iran. He is currently an associate professor in the power electronics group and is the director of Power Electronics and Protection (PEPLAB) laboratory. His major research activities are in the areas of digital signal processing applicable in power systems and power electronics. His current academic interests include a variety of research issues associated with "information and communication technology", "information security" and "power electronics" related topics.

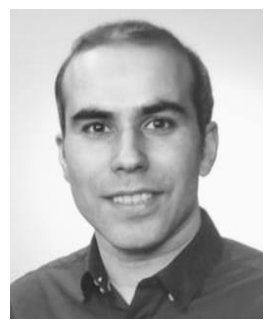

Mahdi Shahparasti (SM, IEEE) received the Ph.D. degree in Electrical Engineering from Tarbiat Modares University, Tehran, Iran in 2014. Between 2015-2021, he was a Postdoctoral Researcher with the Technical University of Catalonia, Barcelona and the University of Southern Denmark, respectively. Currently, he is an Assistant Professor at the School of Technology and Innovations, University of Vaasa. His research interests include hardware design, control, stability and dynamic analysis of power electronic systems, renewable energy resources, and motor drive systems. 